\title{
The Anodic Excursion Peak as a Rapid Way of Measuring the Corrosion of Lead Alloys
}

\author{
J. Lach ${ }^{1}$, A. Czerwiński $i^{2,3, *}$ \\ ${ }^{1}$ Industrial Chemistry Research Institute, Rydygiera 8, 01-793 Warsaw, Poland \\ ${ }^{2}$ Faculty of Chemistry, Warsaw University, Pasteura 1, 02-093 Warsaw, Poland \\ ${ }^{3}$ Biological and Chemical Research Centre, University of Warsaw, Zwirki i Wigury 101, 02-089 \\ Warsaw, Poland \\ *E-mail: aczerw@ chem.uw.edu.pl
}

doi: $10.20964 / 2016.11 .66$

Received: 9 August 2016 / Accepted: 17 September 2016 / Published: 10 October 2016

\begin{abstract}
The corrosion of the positive plate is an important aspect of the lead-acid batteries behavior. Having a fast and reliable way of testing it would improve the process of upgrading and designing new lead-acid batteries. For this reason the relationship between the corrosion resistance of lead alloys and their anodic excursion peaks was investigated. First tests were conducted on disc electrodes made of lead alloys, for which the excursion peaks were measured. Different samples made of the same alloys were corroded electrochemically. Results show that there is a correlation between the excursion peak current and the weight loss during the anodic corrosion of lead-antimony and lead-tin alloys. Moreover, this correlation was confirmed for a complete $2 \mathrm{~V}$ lead-acid battery with collectors made from a commercially used multi-component alloy. The excursion peak is also very similar for solid lead electrodes and electrodes from lead electroplated on reticulated vitreous carbon, which shows that the proposed measurement can be used for lead-acid batteries with reticulated current collectors. The main advantages of the described way of investigating the lead alloy corrosion are: fast measurement and small amount of material required.
\end{abstract}

Keywords: lead acid batteries, corrosion, lead alloys, anodic excursion peak, reticulated vitreous carbon

\section{$\underline{\text { FULL TEXT }}$}

(C) 2016 The Authors. Published by ESG (www.electrochemsci.org). This article is an open access article distributed under the terms and conditions of the Creative Commons Attribution license (http://creativecommons.org/licenses/by/4.0/). 